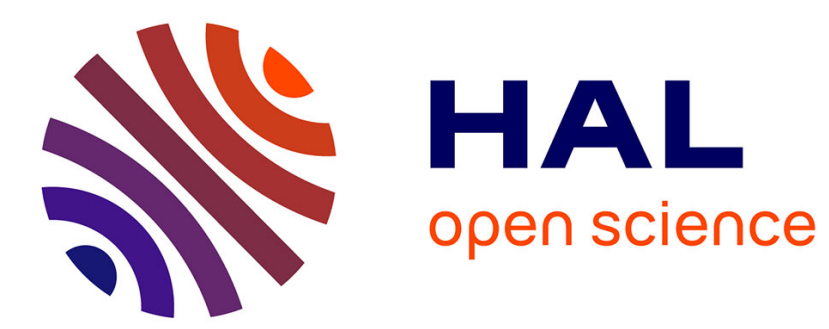

\title{
A conceptual theory of state changes
}

Peter Stockinger

\section{To cite this version:}

Peter Stockinger. A conceptual theory of state changes. Semiotica, 1989, 77 (1-3), pp.137-150. 10.1515/semi.1989.77.1-3.137 . hal-03120763

\section{HAL Id: hal-03120763 https://hal.science/hal-03120763}

Submitted on 25 Jan 2021

HAL is a multi-disciplinary open access archive for the deposit and dissemination of scientific research documents, whether they are published or not. The documents may come from teaching and research institutions in France or abroad, or from public or private research centers.
L'archive ouverte pluridisciplinaire $\mathbf{H A L}$, est destinée au dépôt et à la diffusion de documents scientifiques de niveau recherche, publiés ou non, émanant des établissements d'enseignement et de recherche français ou étrangers, des laboratoires publics ou privés.

\section{(이)(\$)}

Distributed under a Creative Commons Attribution - NonCommercial - NoDerivatives| 4.0 


\section{A conceptual theory of state changes ${ }^{1}$}

PETER STOCKINGER

\section{Introduction}

I will focus in this paper on what John Sowa calls the 'conceptual relations':

In the formal theory there is only one primitive relation called LINK. All others are introduced by definitions. For a practical knowledge representation system, a reasonable number of basic relations should be provided for all the common relations that are used in ordinary language: firstly, case relations also called thematic roles, show how the action or state expressed by verb is related to the entities expressed by subject, object and other complements. They include agent (AGT), patient (PTNT), state (STAT), recipient (RCPT), instrument (INST), destination (DEST), and several others. Secondly, spatial relations include the simple location (LOC) as well as more specific ones that correspond to spatial prepositions such as 'in', 'on', and 'above'. Thirdly inter-sentential relations relate contexts that include one or more conceptual graphs as referents. (Sowa 1987: 6)

I will not discuss the well-foundedness of this typology of conceptual relations. What I retain is the affirmation of the central importance of the casual relations in view of a conceptual representation of knowledge encoded in natural language.

Nevertheless, it is also a well-known fact that one of the weaknesses of semantic theories which work with casual relations is that they cannot attribute a clear conceptual content to this kind of relation. Therefore, such relations are sometimes used quite arbitrarily. On the other hand, we might also consider the fact that different semantic theories use a different number of casual relations.

I think that one of the things most lacking in a theory of casual (or, as I prefer to say, actantial) relations is an explicit theory of state changes which permits us to understand what kind of features or categories are essential to describe actions, acts, events, and states. Such a theory could 
also avoid the quite arbitrary introduction of so-called basic or primitive acts or actions, as is the case in AI research.

Therefore, my purposes are (1) to summarize some essential features or categories which permit us to elaborate an explicit conceptual theory of state changes; (2) to define a certain number of actantial relations or roles which derive from a theory of state changes; and (3) to show some possible links between the conceptual theory of state changes and the theory of cognitive archetypes of Desclés (1985) as well as the localist or thematic relations hypothesis (Jackendoff 1983; Kočura 1987).

\section{Basic features of a conceptual theory of state changes}

State change events in their most elementary form could be represented in the narrative grammar of A. J. Greimas (1979) by the model of the narrative program. According to the logical structure of the narrative program, these events consist of an initial state, a final state, and a change or transition leading from the initial to the final state. If the change can be considered as an intervention of an animate (or at least anthropomorphic) agent, it will be represented by the predicate [DO]. If the change is caused by an inanimate source, the predicate [DO] will be replaced with the predicate [CAUSE].

Examples:

[DO]: John opens the door (intentionally ...)

[CAUSE]: The wind opens the door (*intentionally ...)

If we consider in a little more detail the predicate [DO], we will very quickly encounter the problem of its negation. As the logician G. H. von Wright (1963) has shown it, the expression 'not to do' can be interpreted in the sense of a categorical negation [NOT [DO]], as well as in the sense of a partial negation [FORBEAR]. Somebody who is doing something must also have the ability or the competence not to do it: in other words, [DO] and its partial negation only show the two possible faces of a very special kind of change that implies the presence of an agent who controls his doing. Therefore, the whole conceptual information of controlled events or states must be represented by a somewhat more complex structure as follows:

[DO]: [CONTROL [DO]]

[FORBEAR]:[CONTROL [FORBEAR]]

Let us now consider the categorical negation of [DO], [NOT [DO]]. In 
fact, here again we can distinguish a conceptual ambiguity. The predicate [NOT [DO]] can be considered as synonymous with the absence of an intentional event. If this is the case, we are not confronted with an event at all, but with a state. But [NOT [DO]] can also refer, by extension, to a class of events which are not under the control of an agent: for example, somebody wishes or intends to open the door, but is not able to do it. In order to understand this kind of situation, we have to introduce - besides the non-intentional events and the controlled intentional events - a third category of events, the category of merely intentional but not necessarily controlled events, which are represented as follows:

\section{[DO]: [INTEND [DO]] \\ [FORBEAR]:[INTEND [FORBEAR]]}

Before going further in my discussion about the conceptual description of a certain variety of dynamic and static situations, I will turn now to the formal structure which underlies all three categories summarized above.

If we consider an intentional or non-intentional event as a state change, then it is quite easy to show, with G. H. von Wright, that all events are based on a common logical structure of four transformations (von Wright 1963; Stockinger 1985, 1987):

' $\mathrm{p}$ ' = positive (initial or final) state

' $-\mathrm{p}$ ' = negative (initial or final) state

$\rightarrow=$ transition

(1) $(\mathrm{p} \rightarrow \mathrm{p})$

(2) $(-p \rightarrow p)$

(3) $(\mathrm{p} \rightarrow-\mathrm{p})$

(4) $(-p \rightarrow-p)$

We see that the predicates [DO], [FORBEAR], and [CAUSE] can be replaced with four more specific predicates that indicate on which kind of transformation an event is based.

For example, [DO] can be replaced with:

$$
[\mathrm{DO}] \Rightarrow\left\{\begin{array}{l}
{[\text { MAINTAIN }(\mathrm{p})]} \\
[\operatorname{PRODUCE}](\mathrm{p})] \\
{[\operatorname{PRODUCE}(-\mathrm{p})]} \\
{[\text { MAINTAIN }(-\mathrm{p})]}
\end{array}\right\}
$$

The four transformations underlie not only elementary controlled intentional, merely intentional, and non-intentional events, but also 
composed ones. In fact, an event of the logical form $(p \rightarrow q)$ can be formally recontextualized as follows:

$\mathrm{p}=$ the door is open

$q=$ the window is open

(1) $([p(q)] \rightarrow[(p) q])$

(John holds the door open and also the window)

(2) $([\mathrm{p}(-\mathrm{q})] \rightarrow[(\mathrm{p}) \mathrm{q}])$

(John holds the door open and also opens the window)

(3) $([\mathrm{p}(\mathrm{q})] \rightarrow[(-\mathrm{p}) \mathrm{q}])$

(John closes the door but holds the window open)

(4) $([\mathrm{p}(-\mathrm{q})] \rightarrow[(-\mathrm{p}) \mathrm{q}])$

(John closes the door but opens the window).

This formal structure can also be used, as Dowty has shown (Dowty 1979), to represent processes of spatial dislocations and those that treat exchange situations.

From the conceptual theory of state changes to the representation of semantics of natural language

I want to introduce now the theory of cognitive archetypes of the French linguist J. P. Desclés; this seems to me to be a very good link between the formal architecture of state changes and the localist or thematic relations hypothesis Kočura uses to represent semantics of natural language in the theoretical framework of Sowa's theory of conceptual graphs (Desclés 1985; Kočura 1987; Fargues et al. 1986).

First of all, let me give a more precise temporal definition of the predicates [DO], [FORBEAR], [CAUSE], and their specifying ramifications. If we localize these predicates to a temporal axis of reference, we can distinguish, according to Desclés (1980) and Desclés and Guentcheva (1987), between a (temporal) state, a (temporal) process, and a (temporal) event: a (temporal) state is characterized by an interval opened on both sides, representing a total absence of change; a (temporal) process is characterized by an interval opened on the left side and closed on the right side; and a (temporal) event is characterized by an interval closed on both sides. As Guentcheva and Desclés (1983) have shown, this conceptual organization of temporalized state changes, combined with a conceptual theory of enunciation, permits a satisfying description of the grammatical systems of tense and aspect in languages like Bulgarian, Russian, French, and so on. Such a conceptual system of time and aspect also allows us to 
organize topologically the sequencing features underlying repeated state changes and not-repeated or not-repeatable ones, as mentioned for example by Talmy (1987).

I think that the temporal and aspectual features constitute only one level of the description of state changes. You can find in languages like German or Russian not only lexical, but also morphological expressions that refer to the epistemic or cognitive control of a state change, to the intentional and yet only emotional orientation, to its merely quantificational progress, and so on. To understand these kinds of phenomena, linguists like Deutschbein (1920) and Isacenko (1962) have coined the notion 'Aktionsarten' ('manners of action') - perhaps a quite intuitive notion, but one which depicts, in my opinion, two very important facts: (1) the predicates [INTEND] and [CONTROL] recover in reality a complex internal structure organizing the planning of actions, acts of epistemical judgments and decisions, control of interfering emotional, moral, esthetical, and other attitudes, etc., and (2) the linkage between on one hand merely temporal and aspectual, and on the other hand 'subjective' features expressed by the predicates [INTEND] and [CONTROL].

In fact, one of the great discoveries of the so-called Group of Berlin (Ehlich and Rehbein 1972; Rehbein 1977; Ballmer and Brennenstuhl 1981 ) is that an approximately adequate semantic representation of a very high number of verbal expressions in natural language can only be provided by an underlying theory of action and planning of action - a conception which is quite similar to that prevailing in structural semiotics (Greimas 1966, 1970). Rehbein (1977) and Ballmer and Brennenstuhl (1981) especially have shown that two predicates like [INTEND] and [CONTROL] involve different kinds of emotional, motivational, contractual, epistemic, and other dimensions. These dimensions can be formulated in 'templates' or 'frames' which are organized within a quite simple overall action model as follows:

$[$ [ORIENTATION] $\rightarrow$ [MOTIVATION] $\rightarrow$ [ELABORATION OF GOAL(S) $] \rightarrow[$ PLANNING $] \rightarrow[$ EXECUTION $] \rightarrow[$ RESULT $]$ (Rehbein 1977)

Given such 'templates' or 'frames', and given an overall action model, it is possible to attribute a semantic value to the occurrences of a verbal or nominal expression which may refer to a quite special experiential domain of action, narration, and so on.

Let us turn now to the theory of cognitive archetypes of Desclés. I cannot describe this theory exhaustively here because of its vast formal and theoretical complexity. But its construal principles are quite easy to understand. Desclés hypothesizes that: (1) there are fundamentally spatial 
and qualitative state changes; (2) these two types can be either intentional or non-intentional (logical, physical, etc.) in nature; (3) spatial or qualitative state changes can be either controlled or not controlled by an agent; and (4) the controlled (spatial or qualitative) state changes can express either a one-level or a higher-level control. (A one-level control is a transitive state change - e.g., John opens the door; a higher-level control is a factitive state change - e.g., John makes Paul open the door.) We see that these principle are very similar to our proposals concerning a theory of state changes.

The structure of the most elementary cognitive archetype is shown in Figure 1. We see that it is formally identical with von Wright's theory of state changes; therefore von Wright's theory makes explicit the different possibilities of changes in the most elementary archetype.

There are at least two points which are important for my proposal. (1) As J. P. Desclés has shown it, there is a formal possibility offered by a certain kind of operators of combinatory logic to prove by 'natural deduction' the linguistically motivated character of cognitive archetypes. (2) Desclés positions the theory of cognitive archetypes in the epistemological frame of the localist hypothesis proposed by Gruber (1976), Anderson (1971), Jackendoff (1983), or again Petitot (1985).

In the next chapter I will show that there is also in generative semaritics a possibility of proving a grammatical motivation of conceptual schemes or archetypes of different kinds of state changes.

I will now discuss in a little more detail the localist hypothesis. The assumption of this hypothesis is that different kinds of lexical fields in natural language can be described with a very low number of primitive categories, which are in almost all cases intrinsically perceptive-spatial categories like [PLACE], [PATH], [DISTANCE], and so on (Jackendoff 1983; Petitot 1985). If we then add the perceptive-spatial distinction (static) [LOCATION] and (dynamic) [DISLOCATION], as well as the three spatial dimensions [VERTICALITY], [HORIZONTALITY], and [FRONTALITY], we will obtain the two central models, called sourcegoal-model (Figure 2) and location-model (Figure 3). Together with some basic topological features like open/closed, inside/outside, and adjacency, as well as features referring to the plexity of an object (Talmy 1983), these two models allow the description not only of spatial situations encoded in natural language, but also of non-spatial situations such as temporal, identificational, or possessive (Jackendoff 1983; Kočura 1987).

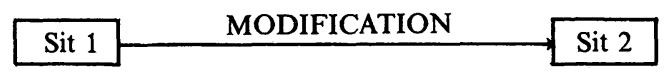

Figure 1. 


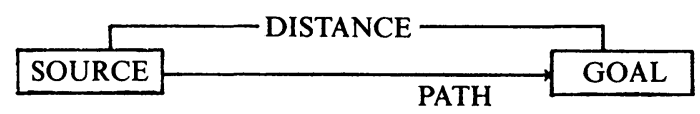

Figure 2.

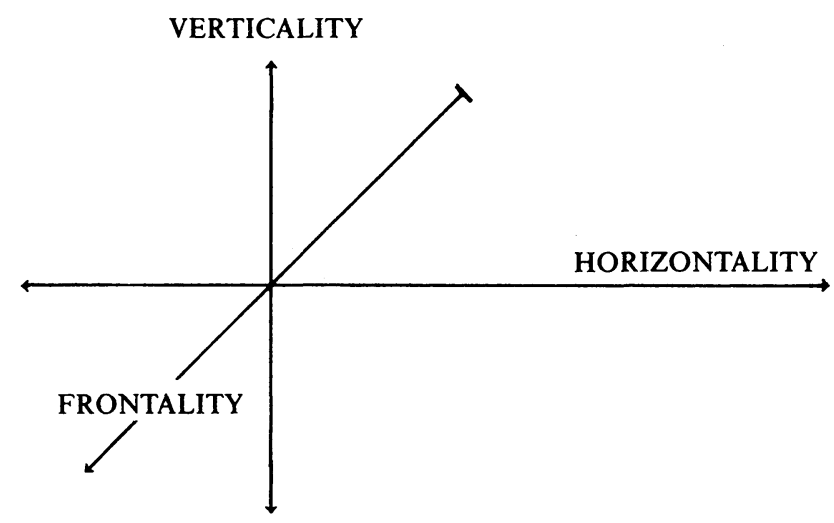

Figure 3.

Nevertheless, the localist hypothesis seems to hide in its usual formulation an intrinsically embarrassing epistemological and descriptive heterogeneity because its viability and operationality depend on the introduction of merely non-spatial categories like [EVENT], [ACTION], or [STATE]. These categories, represented in my paper by predicates like [DO], [INTEND], [CONTROL], and so on, cannot be exhaustively reduced to purely spatial or topological entities: the differences between non-intentional changes and intentional changes, or between merely intentional and controlled intentional changes, are of another nature. We find the same ambiguity in the case theories working with the localist hypothesis: the ergative is not only the source of a state or a state change, but also (contrary to the nominative) an instance which controls a state or state change. In fact, the difference between:

$$
\begin{aligned}
& \text { John dies ('John' = nominative) } \\
& \text { and } \\
& \text { John opens the door ('John'=ergative) }
\end{aligned}
$$

can be described in a localist case theory only by the introduction of features like [ \pm Controlling] or [ \pm Intentional]. The necessity to introduce such features, which do not per se have any relation to a spatial or a 
topological category, shows in fact that the localist hypothesis works only if it admits a rather ambiguous constructional and yet ontological heterogeneity.

It is, however, possible to reduce this heterogeneity. It seems to me that the localist hypothesis, in the form which I have presented, totally eludes the nature of dynamics involved in spatial location, translation, and rotation (Schöne 1980). It is to the great merit of Talmy (1985), Lakoff (1987), and Brandt (1987) to have shown that the nature of this dynamic can be understood with kinesthetic schemes representing the different forms of intensity which underlie each state change. With these considerations we again join the works of the Group of Berlin (Ballmer and Brennenstuhl 1981; Rehbein 1977), which have shown, in the field of lexical semantics, the central importance of the category of intensity for the construction of frames or conceptual models which organize a great number of verbal expressions in natural language. Quite similar to the psycho-dynamical vision of language (Pottier 1987), the category of intensity forms a sort of hat-structure (Figure 4). This structure permits a primarily rough distribution of verbal expressions belonging to one particular model of action, as well as the depiction of the presuppositional or orientation paths proper to such a model.

The representation of state changes in terms of kinesthetic schemes reintroduces the old and well-known problem of patterns of regulation which stabilize biological and symbolic systems (Piaget 1941, 1967; Petitot 1985). It is no longer scandalous to look for such regulative or rhythmic patterns as organize the emergence of cases or actants with different potentials of action and adaptation, as Talmy (1985) and Brandt (1987) have shown with their conception of 'force dynamics' in language.

To come back to the localist hypothesis, it seems to me that its conception in purely perceptive-spatial categories only points to one facet of cognitive activities - those constituted by the outer perceptive

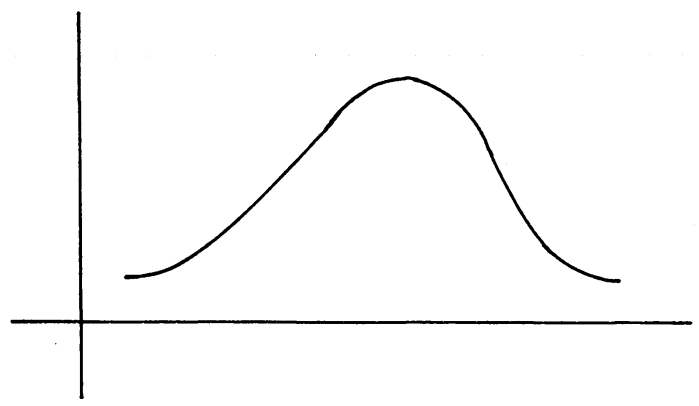

Figure 4. 
apparatus like vision or audition. Another facet of cognitive activities can be depicted by kinesthetic schemes referring to inner sensations like equilibrium, coordination of moves, resistance, propulsion, and so on. Therefore, it is only such an extended conception of the localist hypothesis, including not only perceptive-spatial categories like [PLACE], [PATH], [DIMENSION], and so on, but also kinesthetic schemes, which makes the hypothesis internally and descriptively more homogenous.

These remarks may seem to be quite speculative, but I think that this is not necessarily the case: besides the fact that a lot of work in semantics of verbal expressions has been done (at least implicitly) with the help of kinesthetic schemes, Jackendoff himself - one of the most outstanding defenders of the localist hypothesis - has recently mentioned the same problem in discussing the quite mysterious relations that exist between conceptual structures, bodily sensations, and musical audition (Jackendoff 1987).

\section{The conceptual schemes of state changes and their grammatical motivation}

We have seen that [DO] and [FORBEAR] necessarily presuppose either the predicate [INTEND] or the predicate CONTROL]. The last two predicates intrinsically lack a predicate like [CAUSE] representing nonintentional changes. These distinctive features between non-intentional and intentional and/or controlled changes are also of central importance for the grammatical and lexical description of phrases in natural languages like English or German. J. R. Ross (1972) in particular has shown the inadequacy of logical predicate-functions or of dependency grammar in view of the distinction between intentional and controlled acts and non-intentional changes. In fact, the two phrases:

and

John opens the door (intentionally)

The wind opens the door (*intentionally)

are usually represented as in the two graphs in Figure 5. According to this kind of representation, there is no possibility of distinguishing between intentional/controlled and non-intentional events. Therefore, Ross has proposed a graph representation for intentional and/or controlled events (Figure 6). In Ross's graph we see quite well how the conceptual representation of intentional and/or controlled events takes place in the linguistic universe of a phase structure (Figure 7). According to the improved version of Ross's graph introduced by Dowty (1979), I replace 

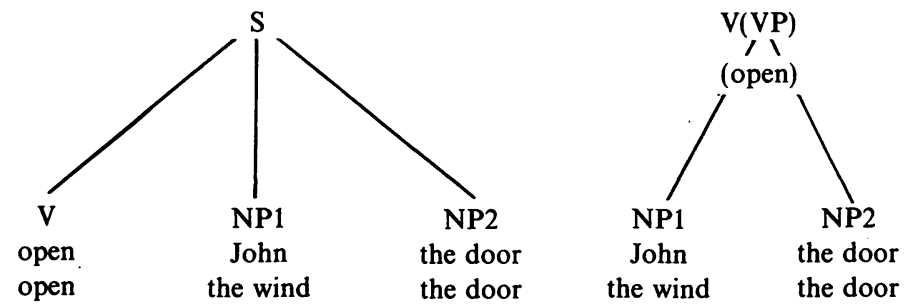

Figure 5.
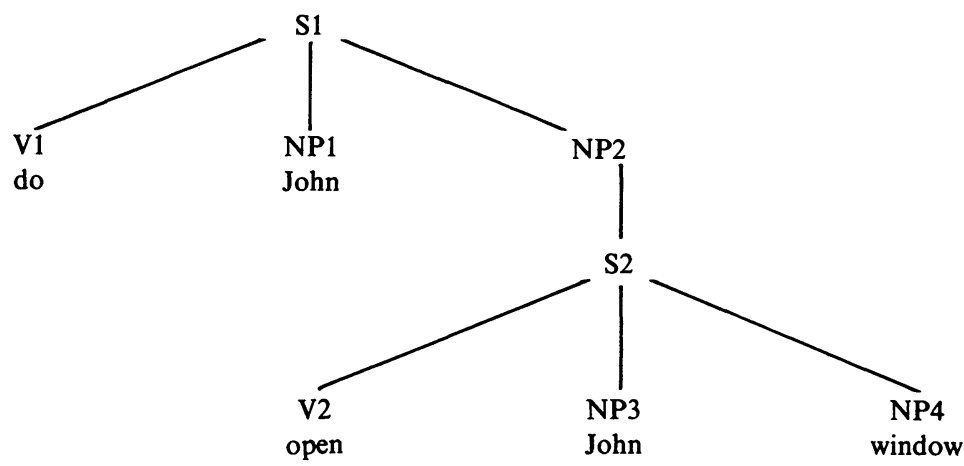

Figure 6.

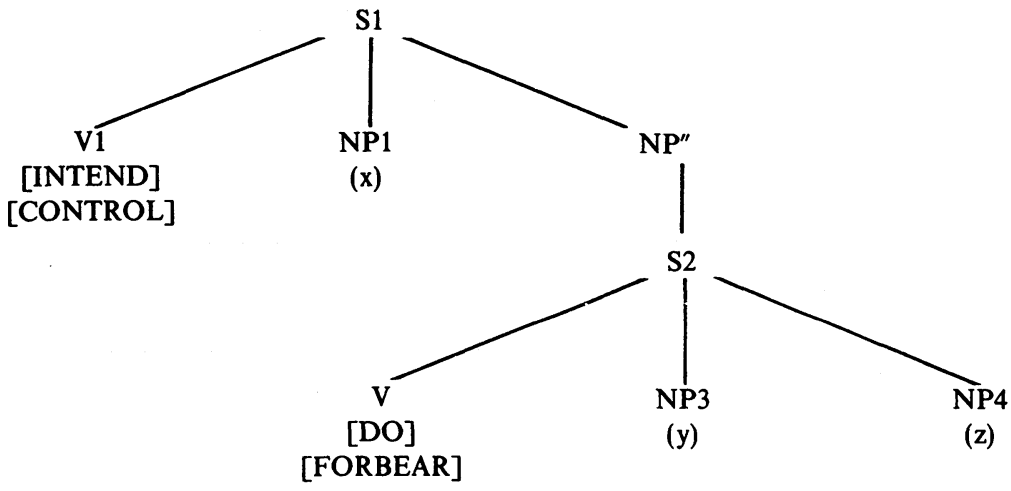

Figure 7.

the representation of the node NP4 as shown in Figure 8. In fact, this representation is more convenient because, as we have seen, the description of events, actions, processes, and so on presupposes the existence of states - final states or initial states. 


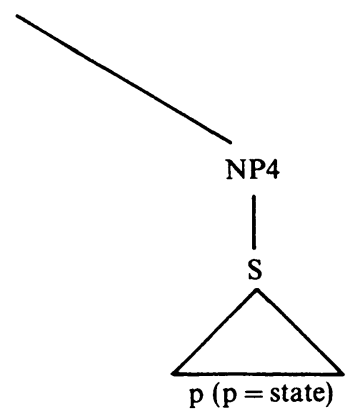

Figure 8.

We are now able to construct conceptual representations of intentional and/or controlled changes:

[CONTROL(x,[DO(y,[BE(z)])])], $[\operatorname{INTEND}(\mathrm{x},[\mathrm{DO}(\mathrm{y},[\mathrm{BE}(\mathrm{z})])])]$,

etc.

\section{Conclusion}

I have introduced the predicate $[\mathrm{BE}]$ as an abstract and primitive one; therefore, it can represent location, possession, descriptive states, and so on. Referring to the researches of linguists like Pottier (1974), Desclés and Froidevaux (1982), and Seiler $(1977,1983)$, I propose the typology shown in Figure 9 as one possibility for representing a certain variety of semantic effects asociated with this kind of situation. I do not pretend that this typology is an exhaustive one, but I think there are some good reasons to accept it: (a) It has a certain logical structure that I cannot describe here,

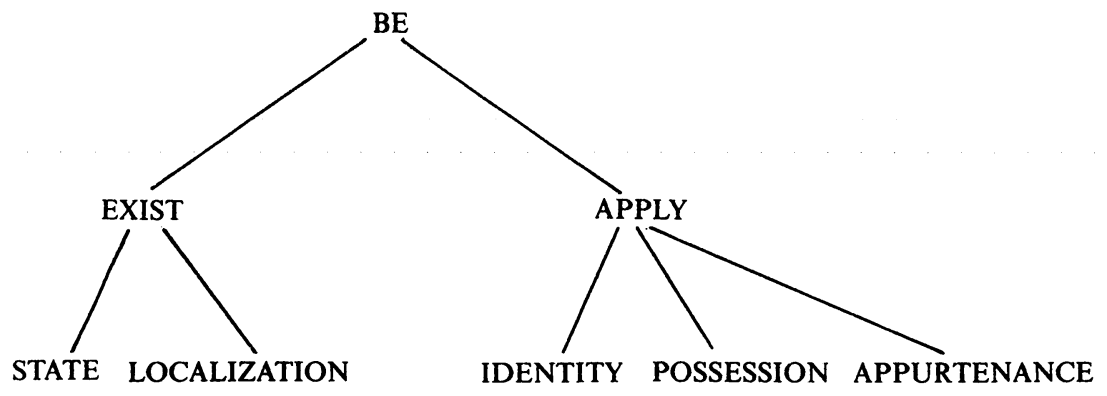

Figure 9. 
but which has been shown, especially by Desclés and Froidevaux (1982). (b) It allows us to identify explicitly different static actantial roles - a work which has not been done in any case theory. (c) It includes, in fact, quite a great variety of empirically attested effects proper to static situations or descriptions of static situations.

The variables in a conceptual scheme like

[CONTROL $(\mathrm{x},[\mathrm{DO}(\mathrm{y},[\mathrm{BE}(\mathrm{z})])])]$

stand for three different actantial roles. Therefore, the sole casual relation [AGENT] in the theory of conceptual graphs in fact includes a variety of different actants which are necessarily associated with their determining predicate. I think that we have to replace the casual relation [AGENT] with the following, more specific actants:

—causing actant: [CAUSE $(\mathrm{x}, \ldots)]$

-intentional actant: $[\operatorname{INTEND}(x, \ldots)]$

-controlling actant: $[\operatorname{CONTROL}(x, \ldots)]$

—executing actant: $[\ldots \mathrm{DO}(\mathrm{x}, \ldots)]$

-static actant(s): $[\ldots \mathrm{BE}(\mathrm{x}, \ldots)]$

If we want to evaluate the adequacy of the control-structure in view of the accomplishment of a state change according to the intentions of the controlling actant, then we have to introduce in our conceptual representation of controlled state changes the function RESULT, permitting us to distinguish between the success and the failure of an action:

$(\exists x, \exists y, \exists z)[C O N T R O L(x,[D O(y,[B E(z)])])]$ RESULT [DO(y,[BE(z)])] ( $x$ controls the doing of $y$ that produces the state of $z$ iff the result of the control of $x$ is the doing of $y$ that produces the state of $x$ )

But we can plainly see that this formula applies only for the successcondition of the doing of $y$, and not for the purposed existence of the state z. Therefore, we have to improve our formula as follows:

$(\exists x, \exists y, \exists z)[C O N T R O L(x,[D O(y,[B E(z)])])]$ RESULT $[\mathrm{DO}(y,[B E(z)])]$ RESULT [BE(z)]

( $x$ controls the doing of $y$ that produces the state of $z$ iff the result of the control of $x$ is the doing of $y$ that produces the state of $x$ and iff the result of the doing of $y$ is the state of $z$ )

It is clear that the function RESULT can only be applied for controlled intentional events; it says nothing about either merely intentional but not necessarily controlled state changes or non-intentional state changes. Furthermore, it applies for only one cognitive archetype, called the transitive archetype. 
If we consider again the two predicates [INTEND] and [CONTROL], then it seems quite clear that they are of a very general nature. Therefore, we have to look for a typology permitting us to introduce some more specific features in order to understand more subtle conceptual and semantic differences of linguistic expressions describing state changes. I think that such a work can be done within the theoretical framework elaborated by the Group of Berlin or the structural semiotics that envisage the conceptual representation of the lexical thesaurus, as I have already mentioned, with the help of an underlying theory of action. But the possibility of justifying this point of view depends on massive empirical descriptions of lexical data.

\section{Note}

1. This article is a revised version of a paper I presented at the 2nd Annual Workshop on Conceptual Graphs, IBM, Paris Scientific Center, September 2-4, 1987. It was translated by Katia Souan.

\section{References}

Anderson, J. M. (1971). The Grammar of Case. Cambridge: Cambridge University Press.

Ballmer, Th. and Brennenstuhl, W. (1981). Speech Act Classification. Berlin, Heidelberg, New York: Springer.

Brandt, P. A. (1987). La charpente modale du sens. Unpublished Thèse d'Etat, Université de Paris III.

Desclés. J. P. (1980). Mathématisation des concepts linguistiques. Modèles Linguistiques 2 (1), 21-56.

-(1985). Représentation des connaissances. Actes Sémiotiques-Documents 7 (69/70).

Desclés, J. P. and Froidevaux, C. (1982). Axiomatisation de la notion de repérage abstrait. Mathématiques et Sciences Humaines 78, 195- 237.

Desclés, J. P. and Guentchéva, Z. (1987). Fonctions discursives. Philosophie, 111-137.

Deutschbein, M. (1920). Die Einteilung der Aktionsarten. Englische Studien 54.

Dowty, D. (1979). Word Meaning and Montague Grammar. Dordrecht: Reidel.

Ehlich, K. and Reihbein, J. (1972). Einige Interrelationen von Modalverben. In Linguistische Pragmatik, D. Wunderlich (ed.). Frankfurt/Main: Fischer.

Fargues, J., Landau, M. C., Dugourd, A., and Catach, L. (1986). Conceptual graphs for semantics and knowledge processing. IBM - Journal of Research and Development 30 (1).

Greimas, A. J. (1966). Sémantique Structurale. Paris: Larousse.

-(1970). Du Sens I. Paris: Seuil.

Greimas, A. J. and Courtés, J. (1979). Sémiotique. Dictionnaire raisonné de la théorie du langage I. Paris: Hachette.

Gruber, J. S. (1976). Lexical Structures in Syntax and Semantics. Amsterdam: North Holland.

Guentchéva, Z. and Desclés, J. P. (1983). L'Aoriste en Bulgare. Cahiers Balkaniques 3, 31-62. Isacenko, A. (1962). Die Russische Sprache der Gegenwart. Teil I: Formenlehre. Halle (Saale): Niemeyer. 
Jackendoff, R. S. (1983). Semantics and Cognition. Cambridge, MA: The MIT Press. -(1987). Consciousness and the Computational Mind. Cambridge, MA: The MIT Press.

Kočura, P. (1987). Conceptual graphs and the thematic relations hypothesis. Unpublished manuscript.

Lakoff, G. (1987). Women, Fire, and Dangerous Things. Chicago: University of Chicago Press.

Petitot, J. (1985). Morphogénèse du sens I. Paris: PUF.

Piaget, J. (1941). Les trois structures fondamentales de la vie psychique: rythme, régulation et groupement. Revue Suisse de Psychologie 1 (1), 9-21.

-(1967). Biologie et connaissance. Paris: Gallimard.

Pottier, B. (1974). Linguistique Générale. Paris: Klincksieck.

-(1987). Théorie et Analyse en Linguistique. Paris: Hachette.

Rehbein, J. (1977). Komplexes Handeln. Stuttgart: Metzler.

Ross, J. R. (1972). Act. In Semantics of Natural Language, D. Davidson and G. Harman (eds.), 70-126. Dordrecht: Reidel.

Schöne, H. (1980). Orientierung in Raum. Stuttgart: Wissenschaftliche Verlagsgesellschaft. Seiler, H. J. (1977). Sprache und Sprechen. München: Fink.

-(1983). Possession as an Operational Dimension of Language. Tübingen: Narr.

Sowa, J. F. (1987). Notation of conceptual graphs. Unpublished manuscript.

Stockinger, P. (1985). Prolégomènes à une théorie de l'action. Actes Sémiotiques-Documents VII (62).

-(1987). De la structure conceptuelle. Unpublished Thèse d'Etat, Université de Paris III.

Talmy, L. (1983). How language structures space. In Spatial Orientation, H. Pick and L. Acredolo (eds.), 225-277. New York: Plenum.

-(1985). Force dynamics in language and thought. Paper presented at the Parasession on Causatives and Agentivity, Chicago Linguistic Society, 21st Regional Meeting.

-(1987). The relation of grammar to cognition. In Topics in Cognitive Linguistics, B. Rudzka-Ostyn (ed.). Amsterdam: John Benjamins.

von Wright, G. H. (1963). Norm and Action. London: Routledge and Kegan Paul.

Peter Stockinger (b. 1956) is Chargé de Recherche at the Centre National de la Recherche Scientifique in Paris. His principal research interests include cognitive sciences, semantics and semiotics, conceptual representation of lexical information and of discursive planstructures, and elaboration of an expert system in the field of legal contracts. Among his publications are Semiotik. Beitrag zu einer Theorie der Bedeutung (1983), 'Intelligence artificielle et théorie sémio-linguistique' (1985), De la structure conceptuelle. Essai d'une description sémio-linguistique des situations statives et dynamiques dans le langage (1987), and 'La nation. Essai d'une représentation conceptuelle du raisonnement idéologique' (1987). 